ARTE E CONTRASSEXUALIDADE: a performance sadomasoquista sob as interpelações queer e (pós) feminista

ART AND CONTRASEXUALITY: the sadomasochistic performance under queer and (post) feminist interpellations

José Juliano Barbosa Gadelha jjulianogadelha@gmail.com

Professor de Antropologia do departamento de Ciências Sociais da Universidade Estadual do Ceará

(UECE)

\title{
Resumo:
}

O artigo discorre sobre os sadismo e masoquismo típicos das culturas BDSM (Bondage, Disciplina/Dominação, Submissão/Sadismo, Masoquismo) praticado como performance art em espaços que vão além dos territórios de arte (museus, galerias etc). $O$ autor tem por interpeladores epistemológicos o Manifesto Contrassexual e o Testo Yonqui de Paul Beatriz Preciado, a filosofia da diferença de Gilles Deleuze e a filosofia do sensível de Jacques Rancière, buscando compreender como os atuais agenciamentos entre arte e contrassexualidade nos desempenhos de alguns agentes performers dos EUA e do Brasil fabricam uma arte que pode ser lida como queer. Os experimentos da análise são as performances de Sheree Rose, Bob Flanagan, Martin O'Brien e Virginia de Medeiros.

Palavras-chave: Arte, Performance, Sadomasoquismo.

\begin{abstract}
:
The article delas with sadism and masocshism as common practices in BDSM (Bondage, Discipline Domination, Submission Sadism, Masochism) cultures practiced as performance art in spaces that go beyond the territories of art (museums, galleries etc.). The author has as epistemological interpellators the works of Paul Beatriz Preciado ("The Contrassexual Manifesto" and "Texto Yonqui"), the philosophy of difference by Gilles Deleuze, and the philosophy of the sensitive of Jacques Rancière, in order to understand how the current assemblages between art and contrassexuality in the performances of some performers and agentes in the US and Brazil shapes na art that could be read as queer. In the analysis, the author focuses on the performances of Sheree Rose, Bob Flanagan, Martin O`Brien and Virginia de Medeiros.
\end{abstract}

Key Words: Art, Performance, Sadomasochism.

Aqui, não farei genealogias de como a Teoria Queer e o pensamento (pós) feminista vem compreendendo o sadomasoquismo, popularmente conhecido pela sigla SM. Essa 
compreensão se encontra por mim desenvolvia no livro "O Sensível E O Cruel"1 do qual este artigo é uma reflexão sobre dois pontos que nele tomei para interpelar a performance SM. O primeiro ponto corresponde à desnaturalização da matriz cisheteronormativa na busca de enfrentamento do caráter compulsório com que essa matriz se ramifica pelas redes em que vivemos. $O$ segundo ponto se situa na política do emancipação de modos de vida oprimidos, a partir da visão da sexualidade como política ou "sexopolítica" 2 . Esses dois pontos que se articulam talvez sejam as ligaduras mais fortes entre as políticas das mulheres e sua participação nas "multidões queer" Trazê-los como interpeladores da performance SM encontra sua razão de ser no fato dessa qualidade de performance, nos diversos modos como se efetua, propiciar o questionamento de normas cisheterossexistas e disparar rumo ao empoderamento dos prazeres dissidentes como forma de arte, o que acaba por configurar a arte da performance SM como meio de combate à opressão cisheteronormativa.

As formas de combate do queer jamais foram lutas estritas à questão de gênero, tampouco a de identidade. Resumir o queer à agenda dos estudos de gênero foi um erro que autores e autoras mundo afora cometeram e ainda cometem. É muito tóxico a modos de vida que existem e traçam sentimentos-ideias de pertencimento pós-identitárias se tornarem objetos exclusivos das categorias de gênero, por mais avançadas que estas últimas estejam atualmente. Já escrevi sobre a limitação do gênero em outros momentos e não quero me repetir ${ }^{4}$. Então, caminharei ao que me parece importante na relação entre arte e sexualidade via performance SM com os tão provocadores modos de vida queer. Passarei ao dissenso que essas performances instauram em relação às normas de prazer vigentes, que tem a cisgeneridade e a heterossexualidade compulsória como bases. Trarei exemplos específicos de performances SM sem esquecer que elas também possuem zonas de reprodução de toda sorte de imagens-clichês,

\footnotetext{
${ }^{1}$ GADELHA, Juliano. O Sensível E O Cruel: uma aprendizagem pelas performances sadomasoquistas. Rio de Janeiro: Editora Metanoia, 2017.

${ }^{2}$ De acordo com Preciado, o biopoder não recai sobre a matéria dos corpos e prazeres sem que as minorias se reapropriem dos dispositivos sexopolíticos (da medicina à representação pornográfica, passando pelas instituições familiares) na produção de processos de subjetivações particulares que interferem no modo como os próprios dispositivos se atualizam. PRECIADO, 2011a.

3 "A sexopolítica torna-se não somente um lugar de poder, mas, sobretudo, o espaço de uma criação na qual se sucedem e se justapõem os movimentos feministas, homossexuais, transexuais, intersexuais, transgêneros, chicanas, póscoloniais... As minorias sexuais tornam-se multidões. O monstro sexual que tem por nome multidão torna-se queer". PRECIADO, $2011 \mathrm{~b}, \mathrm{p} .14$.

${ }^{4}$ Ver GADELHA $(2011 ; 2009)$.
} 
inclusive as dos gêneros e das sexualidades. E mais: o SM se lança como performance art de acordo e contra também os dispositivos do artístico, que a seguir serão refletidos.

Afirmar que existem vários dispositivos de arte consiste em dizer, dentre outras coisas, que a arte cria territórios de reconhecimento que validam exatamente como ela é percebida. Essa validação costuma ter efeito bumerangue porque se, por um lado, o tipo de obra reitera a lógica territorial, por outro lado, o próprio território artístico, via seus agentes físicos-subjetivos, validam o que seria ou não uma obra de arte. Porém, processos criativos que não adquirem o reconhecimento de arte nesses territórios ou artistas que não desejam que seus trabalhos sejam identificados pelos dispositivos de arte são fatos que costumam existir em toda a história da arte, que correspondem exatamente à história da criação de tais territórios que são os responsáveis pelo delineamento das escolas, dos estilos e até mesmo do que seria a vanguarda, ainda que esta última se apresente como afronta à doxa das escolas e dos estilos. Mas o que realmente faria algo ser arte para além dos modelos de arte dos dispositivos? Particularmente, defendo que algo se faz arte quando uma materialidade sensível diversa das materialidades previsíveis do objeto é alcançada, quando a materialidade da obra se abre à possibilidade de ser outra coisa que não exatamente aquilo que se vê, escuta, toca, interage etc. Essa abertura ao possível que jamais esgota a obra permite que ela dure no tempo, resistindo às mudanças de valor das gerações presentes e vindouras. "A arte é o que resiste: ela resiste à morte, à servidão, à infâmia, à vergonha" ${ }^{5}$

A resistência no caso da arte queer, ao ter a cisheteronormatividade como aquilo que é vazado, tornou-se um campo de possibilidades em que os prazeres e as sexualidades abjetas se abrem a uma miríade de maneiras de serem significados e sentidos de outras formas. A materialidade do queer via arte abre na abjeção aquilo que a norma não espera do abjeto sexual, a positividade dele ser encarado como arte, e ainda abre a múltiplas outras possibilidades de reflexão e sensação com aquilo que costumeiramente temos como sujo, perigoso, imoral ou sob outros desígnios do estigma. Uma dessas possibilidades é a reconfiguração do tecido social no que tange às novas formas de contratos sexuais. As multidões queer, ao trazerem outras sexualidades e modos de viver os gêneros como alternativas à heterossexualidade e à cisgeneridade e aos seus

\footnotetext{
${ }^{5}$ DELEUZE, Gilles. Conversações. São Paulo: Editora 34, 1992, p. 215.
} 
respectivos modos contratuais, fabricam aquilo que Paul Beatriz Preciado denomina de contrassexualidade, que concerne nos contratos de prazer fora da norma sexual.

Segundo Preciado ${ }^{6}$, o mundo ocidental moderno coroou a ideia de que nós pessoas humanas devemos seguir um repertório do desejo sexual independente da nossa designação de gênero e, ao mesmo tempo, compreende apenas duas possibilidades para tal designação, a de homem (cisgênero) e a de mulher (cisgênera). O repertório sexual seria um só, a saber, a heterossexualidade como norma que não se alinharia com nada que não for cisgênero. Acrescenta-se a isso o fato de que nem todas as formas de viver a heterossexualidade seriam consideradas normais. Por exemplo, o sadomasoquismo não é visto como normal pela cisheteronormatividade, ainda que ele seja praticado entre pessoas heterossexuais e cisgêneras. Assim, a contrassexualidade é um contra-dispositivo às regulações normativas sobre como viver os prazeres, independente deles estarem na linha cisgeneridade-heterossexualidade.

O queer como contrassexualidade não é uma identidade sexual ou de gênero, mas um campo complexo de disputas e possibilidades das formas dissidentes de prazer. Dessa forma, a arte queer seria, antes de tudo, uma arte contrassexual, ainda que "a eficácia da arte não consiste em transmitir mensagens, dar modelos ou contramodelos de comportamento ou ensinar a decifrar as representações" ${ }^{7}$. Por maior que seja o poder de crítica que uma obra carregue ou possibilite a algum modelo, devemos estar cientes de que a força representativa dessa obra "consiste, sobretudo, em disposições dos corpos, em recorte de espaços e tempos singulares que definem maneiras de ser, juntos ou separados, na frente ou no meio, dentro ou fora, perto ou longe ${ }^{\prime 8}$. Essas disposições espaço-temporais que a arte possibilita é o que abre passagem para a reconfiguração do tecido social pelo trabalho do/da artista. Obviamente, esse trabalho reconfigurador tende a alicerçar embates, mas ele não é feito necessariamente com esse objetivo. Uma obra pode ter um caráter político inimaginável pelo/pela artista que a criou ou simplesmente não passar a idealização política que ele/ela desejou para sua criação. No entanto, os/as artistas queers, muitas vezes, parecem ter a intenção de afronta à matriz cisheteronormativa enquanto outros/outras artistas elaboram de maneira menos pretensiosa suas obras, de acordo com os

\footnotetext{
${ }^{6}$ Ver PRECIADO (2011a).

${ }^{7}$ RANCIÈRE, Jacques. O espectador emancipado. São Paulo: Martins Fontes, 2012, p. 55.

${ }^{8}$ Ibid., p. 55.
} 


\section{ARTE E CONTRASSEXUALIDADE: A performance sadomasoquista sob as interpelações queer e (pós) feminista}

modos de vida queer, que em si já são ofensivos a tal matriz. Às vezes, essa última espécie de produção acaba por ter poder de combate maior do que as intencionais.

A força representativa das obras queers se encontra na capacidade de novas disposições dos corpos, dando visibilidade positiva ao insulto, àquelas pessoas marginalizadas pelo poder. Ela consiste em novo recorte de espaços e tempos singulares, dificultando a cisheteronormatividade na sua definição das maneiras de ser, juntos ou separados, na frente ou no meio, dentro ou fora, perto ou longe. No entanto, além da força representativa da arte, existe a intensiva, que configura o "plano de imanência" ${ }^{9}$ da obra, sendo tal plano o responsável pela resistência da arte frente aos tempos. Chegamos ao ponto em que proponho a definição de política da arte sob a subdivisão em duas forças, a representativa e a intensiva. 0 caráter representativo da arte pode ser político, enquanto o intensivo é sempre político, no sentido de uma política menor. 0 primeiro se mostra político quando engendra o enfrentamento direto aos modelos no caminho de uma possível redefinição da ordem - força macropolítica da arte. Já o segundo, sempre pertence a uma política minoritária, dos devires e das resistências que despertam a produção de sensações - força micropolítica da arte. E é na micropolítica da obra que se encontra a capacidade dela em dizer outra coisa do que supostamente representaria e a não capacidade da arte de se prender aos contornos que paralisam nossa capacidade de vibrar com o mundo.

De volta à discussão sobre o caráter intencional ou não da obra, a produção do SM enquanto arte, em especial como performance art, caminha nessa dualidade. Ora a produção de alguns e algumas performers SM vem com propostas diretas de enfrentamento ao contrato heterossexual e cisnormativo, ora vem com outras preocupações que só tocam nas mesmas questões de enfrentamento, pois o próprio SM, por mais que reproduza modelos cisheteronormativos, é em si mesmo um estilo de vida tido como abjeto ou queer por sua estranheza às formas consideradas normais de viver o prazer. A matriz cisheteronormativa não é um dispositivo que simplesmente legitima a cisheterossexualidade como norma a ser seguida, mas que dita tipos específicos do que seriam as boas e saudáveis formas de viver a

\footnotetext{
${ }^{9} \mathrm{~A}$ imanência como a força que transborda dos seres. Ela tende a produzir um plano de intensidades, que Deleuze e Guattari denominaram de plano de imanência, em contraste à ideia de um plano de consistência, estruturado pelas representações. Para mais informações sobre a noção de plano de imanência e de consistência ver DELEUZE; GUATTARI (1992).
} 
cisheterossexualidade. Ela se encontra acoplada a outros dispositivos, tais como o religioso, que dita dogmas sobre casamento, família, iniciação sexual, e o dispositivo econômico, que insere modos de consumo do sexo e de estimulação do prazer. Esses acoplamentos configuram maneiras específicas de controle e opressão nas quais nem todos os prazeres entre agentes heterossexuais e cisgêneros são legitimados.

Um exemplo de artista que vem compondo, no cenário nacional brasileiro, uma imagem de produção de obras contrassexuais é Virginia de Medeiros. No entanto, precisa-se de cautela antes de identificarmos que a artista idealiza suas criações via alguma espécie de ativismo queer ou (pós)feminista, apesar de tais criações ora trazerem o tom de questionamento à cisheteronormatividade bem acentuado, ora transparecerem esse tom apenas como sintoma do caráter dissidente tão inerente aos modos de vida trabalhados por Virginia. Há momento em que seria difícil desvincular a obra da artista de um reconhecimento queer. Destaco aqui duas criações multimídia de Virginia: 1) Studio Butterfly E Outras Fábulas; 2) Jardim das Torturas.

A primeira foi apresentada na 270 bienal de São Paulo, consistindo em um estúdio carregado, dentre outras coisas, de fotos pertencentes a travestis e transexuais. Além de fotografias, a instalação apresentava o mundo $\operatorname{trans}^{10}$ por meio de outros modos de exposição, em especial através de recursos audiovisuais. Virginia conseguiu parte do material da instalação por meio de uma troca que consistia em levar as trans a um estúdio onde a artista as entrevistava e, posteriormente, realizava um book fotográfico, semelhante ao das top models, doado a cada entrevistada, que, por sua vez, cedia alguma(s) foto(s) da sua história de vida - em síntese, havia uma troca entre as fotos feitas pela artista e outras trazidas pelas trans. Studio Butterfly configura um mundo de experiências fora da norma sexual e de gênero para além da lógica do estigma. Virginia procurou fazer com que o espectador e a espectadora do Studio Butterfly sentissem a força daquelas experiências sem ser pelos sentidos dos estereótipos, o que acabou por arrancar a obra da artista do lado testemunhal da vitimização ou do preconceito que ronda as vidas trans, fazendo do próprio estúdio outra fábula sobre/com aquelas vidas.

\footnotetext{
${ }^{10}$ Uso a palavra trans em referência a drag queens, cross dressers, travestis, transexuais e transformistas não porque essas pessoas sejam ou formem uma só coisa, mas porque são pessoas que em diversas localidades do Brasil se valem da palavra trans como símbolo de pertencimento, ainda que hajam algumas dissidências entre essas pessoas acerca do uso desse símbolo.
} 


\section{ARTE E CONTRASSEXUALIDADE: A performance sadomasoquista sob as interpelações queer e (pós) feminista}

Já em Jardim das Torturas, Virginia construiu uma espécie de masmorra dentro da galeria Nara Roesler, situada na cidade de São Paulo. O público podia ver, por entre algumas aberturas na masmorra, outro ambiente que consistia numa espécie de câmara na qual Virginia se encontrava quase nua, amarrada e amordaçada. O restante da galeria foi ocupado por uma série de fotografias e objetos que figuravam o universo BDSM, alguns elaborados pela artista, outros adquiridos por ela.

Virginia é o exemplo de artista que mergulha em universos marginalizados e com eles consegue fazer arte que não seja mimética, diferindo da pessoa do pesquisador ou da pesquisadora que procura retratar modos de vida. A artista visa, a partir de modos de vida considerados abjetos, criar outro território, e é assim que o SM emerge em Jardim das Torturas, pois ali ele não é mais o sadomasoquismo do BDSM e sim uma fauna das delícias e das dores, uma geografia dos desejos dissidentes que aproxima o espectador ou a espectadora não SM ao universo BDSM por aquilo que todas as pessoas têm em comum de alguma forma, a nossa própria geografia do desejo. Ao se colocar numa posição de masoquista numa câmara, Virginia delineia uma cartografia íntima de si que nos devolve a sensação de que somos todos seres desejantes em que normal e o dito anormal são facetas dúbias de uma mesma moeda.

Por mais que as obras da artista possibilitem um diálogo crítico das normas sexuais e de gênero, colocando certos modos de subversão na pauta das reflexões, tudo isso não parece ser o objetivo principal das criações de Virginia, tudo isso difere, por exemplo, de trabalhos de artistas que, muitas vezes pesquisando universos semelhantes aos estudados por Virginia, fazem questão de afirmar uma posição política de subversão da norma e de valorização da diferença, artistas que, não raramente, se autoafirmam ou são reconhecidos como queer.

O casal norte-americano Sheree Rose e Bob Flanagan consistia num exemplo clássico de performers que, nos seus experimentos sobre/com universos marginalizados, traziam claros objetivos políticos de enfrentamento às normas em prol do que eles chamavam de novas formas de viver o sexo e o amor. "Rose é uma lenda de várias cenas dos metrôs de Los Angeles. Shows de punk, grupos feministas, cenas de leitura de poesia, clubes de fetiche, eventos de arte de desempenho subterrâneo - Ela foi lá e fez isso como uma participante ativa e também como uma 
documentarista"11. A trajetória de Rose passa pelo movimento feminista da década de 1970, em que a artista-ativista dialoga com facções radicais que encaravam o lesbianismo como modo de ser feminista e o homem como figura inimiga do movimento - fatos que para Rose jamais foram verdades a serem defendidas e, assim, ela distancia-se de tais grupos em busca de fazer um ativismo em prol das mulheres que não se resumisse apenas à classe de mulheres lésbicas. Após um divórcio, Rose começa a aconselhar mães solteiras sobre educação e independência econômica. Na esteira de uma trajetória de ativismo constante e plural, Rose encontra o escritor e performer Bob Flanagan, com quem começa um romance que somente anos mais tarde culminaria na exibição do casal em performances SM para um público mais amplo do que o de costume. "Eles estavam juntos há anos antes que a relação se transformasse em uma prática da arte, e seu ativismo foi, a princípio, um ativismo explicitamente sexual localizado para suas vidas pessoais e ao seu ativismo dentro e em nome da comunidade BDSM"12.

Rose, em entrevista a também artista e feminista Tina Takemoto para o Women \& Performance: a journal of feminist theory, disserta sobre seu relacionamento com Flanagan no que tange à realização de performances SM. Vejamos o trecho da entrevista que deixa isso mais latente:

Eu diria que existem três fases principais no nosso relacionamento. A primeira fase foi a nossa vida pessoal - só ele e eu e todas as coisas loucas, selvagens e divertidas que fizemos juntos durante os primeiros dois anos. Eu mesma fotografei tudo, essa documentação era só para nós. Os próximos cinco anos, a segunda fase, foram gastos na organização da comunidade sadomasoquista, o que não tinha sido feito antes. O SM foi um aspecto muito importante de nossas vidas. Nós acreditávamos nele o suficiente para derramar toda a nossa energia para fazer um movimento nacional SM e uma criação de espaços públicos e comunitários para ele. Nós nos tornamos porta-vozes de sadomasoquismo, dando palestras e demonstrações de sensibilização sobre a comunidade SM. Hoje em dia, tem ido muito mais longe do que esperávamos. Mas, naquela época, o movimento SM estava apenas começando. $E$, porque temos essas boas respostas dentro da comunidade SM, que flertamos com a ideia de trazer o SM para fora do mainstream. Esse foi o início da terceira fase, a fase de arte. ${ }^{13}$

11 DOYLE, Jennifer. Sheree Rose: A Legend of Los Angeles Performance Art. Disponível em:

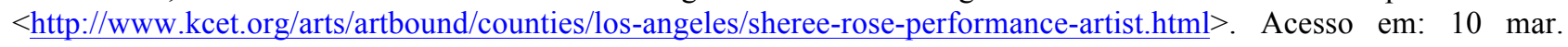
2015.

12 DOYLE, Jennifer. Sheree Rose: A Legend of Los Angeles Performance Art. Disponível em: $<$ http://www.kcet.org/arts/artbound/counties/los-angeles/sheree-rose-performance-artist.html $>$. Acesso em: 10 mar. 2015.

${ }^{13}$ TAKEMOTO, Tina. Love is still possible in this junky world: Conversation with Sheree Rose about her life with Bob Flanagan. Women \& Performance: a journal of feminist theory, 19:1, 95-111, 2009, p. 101, tradução minha. 


\section{ARTE E CONTRASSEXUALIDADE: A performance sadomasoquista sob as interpelações queer e (pós) feminista}

O que podemos dizer do trecho da entrevista destacado? Na primeira fase do casal, encontramos o SM como estilo de vida. Já na segunda, percebemos uma busca do empoderamento desse estilo, ainda que aparentemente para Rose essa emancipação estivesse circunscrita à esfera dos coletivos BDSM, sendo uma luta feita com e para esse coletivo. Quando o casal retoma os seus registros da primeira fase na segunda fase, analisando e divulgando essa documentação em palestras e em outros modos de comunicação, quase sempre seguidos de exemplos de novas experimentações SM, o que encontramos é uma ânsia de reconfigurar o tecido da sociedade norte-americana para novas espaço-temporalidades do desejo. A garantia do SM como movimento nacional que possibilitasse criar espaços públicos e privados culmina, então, numa fase macropolítica dos experimentos do casal que teve a arte como matéria de expressão. $\mathrm{A}$ terceira fase não é aquela em que Rose e Flanagan descobriram a arte, mas a que o casal fez da arte uma matéria de expressão de objetivos claramente políticos em prol de um modo de contrassexualidade.

Esse caráter político que o casal conferiu à sua vida íntima pela arte frequentemente ultrapassava as fronteiras do SM, adentrando outras questões fortes como a morte, a doença, a fragilidade e a crueldade da própria vida. Essas outras questões estão diretamente ligadas à própria doença de Flanagan, que sofria de fibrose cística. Isso tudo fica bastante latente na instalação-performance idealizada pelo casal, mas de desempenho de Flanagan, intitulada Visiting Hours, em que uma sala de hospital foi montada mediante uma série de objetos e outras microinstalações que figuravam o universo SM particular do casal e a relação de Flanagan com a sua doença. Em determinados momentos, Flanagan era suspenso por correntes e realizava alguns movimentos, ficando completamente nu. Havia horas em que ele era deitado na cama e conversava com o público. Tudo isso dentro de museus. A instalação-performance estreou no Museu de Santa Mônica, na Califórnia, em 1993 e foi montada no ano seguinte no Novo Museu de Arte Contemporânea de Nova lorque e no Museu da Faculdade de Belas Artes de Boston no ano de 1995.

Com essa qualidade de obra e com outras sempre de teor profundamente contrassexual, tais como o documentário Sick: The Life and Death of Bob Flanagan, Supermasochist, dirigido por Kirby Dick, e alguns textos publicados pelo casal dos quais o mais conhecido é o livro The Wedding of Everything, escrito por Flanagan e recheado de fotos feitas por 
Rose, o casal imediatamente passou ao reconhecimento de artistas queer e, no caso particular de Rose, de artista feminista-queer, apesar de se tratar de um casal heterossexual. Isso sintomatiza uma das vertentes de pertencimento ao que os agentes norte-americanos denominam de queer e que não corresponde necessariamente a ser gay, trans ou lésbica. Para a sociedade norteamericana, o queer vai além do aparentemente exótico, do visivelmente estranho, da forma ainda que disforme, do contorno ainda que imperfeitamente traçado. A estranheza do queer se encontra naquilo que nele difere de qualquer contorno de gênero, sexo ou sexualidade, na força intensiva da abjeção que imediatamente gera repulsa às subjetividades mais domesticadas. Tratase de um termo percepto porque a população dos EUA não desenvolveu a gíria britânica queer com essa consciência da diferença, que nós podíamos chamar de uma consciência filosóficapolítica da alteridade sobre/com as forças desviantes. O queer é um termo percepto porque vem como nomeação quase inconsciente. Trata-se de uma percepção dos sentidos frente ao outro que, por condutas e aparências desviantes, fere a condição normatizada de nos afetar intimamente com o outro. Como insulto, o queer é o escarro das subjetividades que se ressentem diante de outras maneiras de experimentar os afectos entre os corpos. E se tomarmos a clássica lição psicanalítica de que o inconsciente se estrutura como linguagem, podemos até ver o queer como o termo que o inconsciente recalcado dos EUA e o da Inglaterra acharam para estruturar como linguagem todo o desprezo ou ódio para com aquilo que fere as suas respectivas moralidades sexual e de gênero. Diante de tudo isso, traduzir o queer como simplesmente homossexualidade, bisexualidade, transgenderismo, pansexualidade etc é matar a força da diferença dos modos de vida queer, fazê-la seguir uma identidade.

Pertencemos às multidões queer quando deixamos de nos prender a algo sexualmente significante, quando nos tornamos estranhos às normas sexuais sem sermos engolidos e engolidas completamente pelas identidades sexuais e de gênero, inclusive as parodiadas pela abjeção, porque não raramente $\mathrm{o}$ abjeto também se reconhece pelas identidades do estigma a ele conferidas, tais como a do viado e a da sapatão. E a definição de queer não seria mais uma dessas identidades abjetas? Ela até poderia ser se não agisse como um insulto transversal que atravessa todas as outras palavras insultuosas referentes às sexualidades minoritárias, sem configurar uma espécie de termo guarda-chuva para todas as abjeções, o que, se acontecesse, facilmente a fecharia no gueto. Como nos adverte Preciado: "Aos que se agitam sob a ameaça de guetização, os 


\section{ARTE E CONTRASSEXUALIDADE: A performance sadomasoquista sob as interpelações queer e (pós) feminista}

movimentos e as teorias queer respondem por meio de estratégias ao mesmo tempo hiperidentitárias e pós-identitárias" ${ }^{14}$.

Quando passamos das multidões queer às artes que tomam os modos de vida das pessoas e dos coletivos que configuram tais multidões como meios do processo de criação, o caso do reconhecimento da obra como arte queer recai sobre a questão identitária e não se concentra na potência daquelas contrassexualidades. Reconhecimento que nem sempre vem ou é aceito pelo próprio ou pela própria artista, pois, muitas vezes, esse reconhecimento vem por forças externas do dispositivo da arte ou de outros territórios, tais como os do ativismo ou da academia especializada em estudos de gênero. No entanto, a força da obra queer se encontra de fato em como o seu criador ou a sua criadora captou as sensações daqueles modos de vida abjetos e as devolveu de alguma maneira estética, e, se esta captação foi possível, podemos apostar que as forças do devir-queer estão agindo pela obra. Em geral, elas agem de forma a lançar um efeito comum, embora a estética possa mudar radicalmente de uma obra para outra, de artista para artista. As criações de forte potência queer tendem a devolver a sensação de que somente não sendo apreendidos e apreendidas pelos contornos dos gêneros, dos sexos e das sexualidades é que causamos de fato um curto-circuito na cisheteronormatividade. Esta, como rede, configura tanto as identidades normalizadas como aquelas do estigma, tomadas pelas multidões queer como estratégia política hiperidentitária.

O contrário de uma retomada da identidade insultuosa emerge nas artes queer pelo caráter de deriva nos modos de experimentar o sexo e a intimidade que artistas efetivam por meio de suas obras, como o casal Rose e Flanagan, que passava ao espectador e à espectadora o exemplo da possibilidade de renegociar o contrato sexual imposto pela cisheteronormatividade. Esses artistas-ativistas "escreveram contratos, por exemplo, descrevendo as obrigações do Flanagan como um escravo e as obrigações de Rose para ele - esses documentos estruturam sua relação de formas que eram ao mesmo tempo prática e sexy ${ }^{\prime 15}$. A contrassexualidade do casal era documentada para além da performance com nítidos objetivos de emancipação social pela arte, deslocando a heterosexualidade dos seus primados naturais (a vida sexual como restrita à esfera

\footnotetext{
${ }_{15}^{14}$ PRECIADO, 2011b, p. 15.

15 DOYLE, Jennifer. Sheree Rose: A Legend of Los Angeles Performance Art. Disponível em: $<$ http://www.kcet.org/arts/artbound/counties/los-angeles/sheree-rose-performance-artist.html $>$. Acesso em: 10 mar. 2015.
} 
doméstica, os prazeres dissidentes como doenças etc) e a pondo em deriva num oceano de desejos incertos. "Eles procuraram recuperar tudo o que o contrato conjugal remove na sua naturalização das estruturas de relações domésticas - eles encontraram uma maneira de renovar constantemente seu relacionamento" ${ }^{16}$. Todas essas ações abriram passagem para emergências de novos e novas performers SM nos EUA. Após a morte de Flanagan, Rose retoma um projeto antigo intitulado DoWith Me What You Will e o realiza com o jovem performer Martin O'Brien, que serve como uma espécie de filho de Rose por 24 horas em um desempenho no qual Rose, como uma mãe sádica, exerce uma série de torturas no jovem Martin.

Se as performances SM de Rose, tanto com Flanagan como com O’Brien, alcançaram os objetivos desses artistas é algo que mereceria outro estudo, o que me interessa ao discutir com esses trabalhos é a compreensão da política contrassexual da performance SM que pode ser algo pensado desde a idealização do desempenho ou vir como sintoma da própria realidade SM transfigurada em arte, como a performance de Virginia de Medeiros em Jardim das Torturas transfigurou o SM. Seja como for, as performances SM do casal norte-americano e as de Virginia de Medeiros se aproximam de uma política queer ao expressarem como um estilo de vida ainda encarado como abjeto ou estranho - o sadomasoquismo - possibilita a abertura para o questionamento das normas de sexualidade, prazer e intimidade ainda vigentes em nossas sociedades por mais que a ideia de queer passe por constantes releituras dos contextos em que, de alguma maneira, ela chega.

\section{Referências}

DELEUZE, Gilles. Conversações. São Paulo: Editora 34, 1992.

DELEUZE, Gilles; GUATTARI, Félix. O que é a filosofia. Rio de Janeiro: Editora 34, 1992.

DOYLE, Jennifer. Sheree Rose: A Legend of Los Angeles Performance Art. Disponível em: <http://www.kcet.org/arts/artbound/counties/los-angeles/sheree-rose-performance-artist.html>. Acesso em: 10 mar. 2015.

16 DOYLE, Jennifer. Sheree Rose: A Legend of Los Angeles Performance Art. Disponível em: $<$ http://www.kcet.org/arts/artbound/counties/los-angeles/sheree-rose-performance-artist.html $>$. Acesso em: $10 \mathrm{mar}$. 2015. 
GADELHA, Juliano. O Sensível E O Cruel: uma aprendizagem pelas performances sadomasoquistas. Rio de Janeiro: Editora Metanoia, 2017.

. A montagem como ritual ou como nasce uma drag queen. In: RODRIGUES, Lea Carvalho (Org.). Rituais, dramas e performance. Fortaleza: Editora UFC, 2011.

Masculinos em mutação: a performance drag queen em Fortaleza-CE. 2009. 262 p. Dissertação de mestrado - Programa de Pós-Graduação em Sociologia, Universidade Federal do Ceará, Fortaleza, Ceará, 2009.

PRECIADO, Beatriz. Manifesto contrasexual. Barcelona: Anagrama, 2011a. . Multidões Queer: notas para uma política dos "anormais". Revista de Estudos Feministas, v. 19, n. 1, p. 11-20, janeiro-abril/2011b.

. Testo Yonki. Madrid: Editorial Espasa Calpe, 2008.

RANCIÈRE, Jacques. O espectador emancipado. São Paulo: Martins Fontes, 2012.

TAKEMOTO, Tina. Love is still possible in this junky world: Conversation with Sheree Rose about her life with Bob Flanagan. Women \& Performance: a journal of feminist theory, v. 19, n.1, 95111, 2009.

Artigo submetido em 30/06/2016, e aceito em 23/02/2017. 